\title{
ESTIMATION OF SALIVARY TUMOR NECROISIS FACTOR-ALPHA LEVEL IN PATIENTS WITH EROSIVE ORAL LICHEN PLANUS (A CASE CONTROL STUDY)
}

\author{
Mona N Elsayed ${ }^{1} B D S$, Naguiba M Elsayed ${ }^{2} P h D$, Sahar E Riad ${ }^{3} P h D$, Sabah A Mahmoud ${ }^{4} P h D$
}

\section{ABSTRACT}

INTRODUCTION: Oral lichen planus (OLP) is a relatively common chronic inflammatory and a potentially malignant disorder of oral mucosa. Tumor necrosis factor-alpha (TNF- $\alpha$ ) has been pointed as a key cytokine in OLP.

OBJECTIVES: To evaluate whether the salivary levels of TNF- $\alpha$ were changed in patients with erosive oral lichen planus (EOLP).

METHODOLOGY: A total of fourteen cases of EOLP with and without dysplastic changes, along with seven age matched healthy controls were included in this study. Samples of unstimulated saliva was collected, centrifuged and analyzed with enzyme linked immunosorbent assay (ELISA).

RESULTS: There was a statistically significant increase in the salivary levels of TNF- $\alpha$ in patients of the two study groups when compared to the control group.

CONCLUSIONS: TNF- $\alpha$ plays a role in pathogenesis and carcinogenesis of EOLP, and can be used as a useful marker and indicator for subjects at high risk to develop OLP as a potentially malignant lesion.

KEYWORDS: Oral lichen planus, Potentially malignant, Tumor necrosis factor, Saliva.

1- B.D.S (2003). Department of Oral Medicine, Periodontology, Oral Diagnosis and Radiology, Faculty of Dentistry, Alexandria University.

2- Professor at Department of Oral Medicine, Periodontology, Oral Diagnosis and Radiology, Faculty of Dentistry, Alexandria University.

3- Professor at Department of Oral Pathology, Faculty of Dentistry, Alexandria University.

4- Professor and Head of Department of Biochemistry, Faculty of Medicine, Alexandria University.

Corresponding author:

E-mail: mona.nasr36@gmail.com

\section{INTRODUCTION}

Oral lichen planus (OLP) is a chronic, inflammatory disease (1). OLP has most often been reported in middle aged patients (2). Women account for $60 \%$ to $75 \%$ of patients with OLP (3). It can be classified into six types: reticular, atrophic, plaque like, papular, bullous and erosive. The buccal mucosa, dorsum of the tongue and the gingiva are commonly affected (2).

The World Health Organization (WHO) classifies OLP as a "potentially malignant disorder" with unspecified malignant transformation risk and suggests that OLP patients should be under close monitoring (4).

Several contributing predisposing factors might be involved in the pathogenesis of lichen planus. Earlier studies have implicated stress, anxiety, depression as possible factors. Familial cases of OLP have been reported and role of genetic predisposition was considered (5).

The cause of OLP is still unknown, but cell-mediated immune dysfunction is implicated in the complex etiopathogenesis of this disease. Large amounts of cytokines released by affected keratinocytes and the associated inflammatory elements play a key role in the selective recruitment of the $\mathrm{T}$ lymphocytes. T-cell dominated infiltrate in the subepithelial region, which characterizes OLP, induces further release of cytokines (6).

A mixed cytokine profile has been demonstrated with elevated concentrations of interleukin (IL)-2, IL-6 and IL10 , as well as tumor necrosis factor-alpha (TNF- $\alpha$ ) within the subepithelial infiltrate in OLP patients (7).

TNF- $\alpha$ is a multifunctional cytokine that plays a prominent role in immune response and host defense (8) and stimulates angiogenesis (9). It has been identified as an important mediator of cancer development (10).

TNF- $\alpha$ has always been pointed as a key cytokine in OLP (11). High serum levels of TNF- $\alpha$ were detected in all patients with OLP in comparison with its hardly detectable levels in control subjects (12).

In our present study data characterizing the pattern of TNF- $\alpha$ production in whole saliva of patients with erosive oral lichen planus (EOLP), with and without dysplastic changes was followed, evaluating the difference in the salivary levels of TNF- $\alpha$ in EOLP with and without dysplasia compared to its levels in saliva of healthy subjects.

\section{MATERIALS AND METHODS}

In the present case control study, 21 subjects aged above 30 years of both sexes were selected from the outpatient clinic of the Department of Oral Medicine, 
Periodontology, Diagnosis and Radiology, Faculty of Dentistry, Alexandria University.

\section{Ethical considerations}

Approval was taken from the ethical committee in the Faculty of Dentistry, Alexandria University, where the study was conducted. All subjects were informed by verbal explanation of the study design, procedure to be performed and were asked to fill a consent form and medical chart to confirm that they are fit to participate in the study.

\section{Inclusion criteria}

Males and females aged above 30 years, clinical diagnosis of symptomatic erosive oral lichen planus, histological confirmation of erosive oral lichen planus, with and without signs of dysplasia, acceptance and signature of informed consent.

\section{Exclusion criteria}

Patients with systemic diseases as diabetes, viral hepatitis and cardiovascular conditions, those with lichenoid reaction caused by amalgam filling or certain drugs, any systemic or topical treatment suppressing the immune system such as steroids or other immunosuppressive drugs and smokers.

Subjects included were divided into 3 groups; group I consisted of 7 patients diagnosed clinically and histologically with EOLP without dysplasia (Figure 1 and 2), group II consisted of 7 patients diagnosed clinically and histologically with EOLP with dysplastic changes (Figure 3 and 4) and group III consisted of 7 healthy subjects serving as control group.

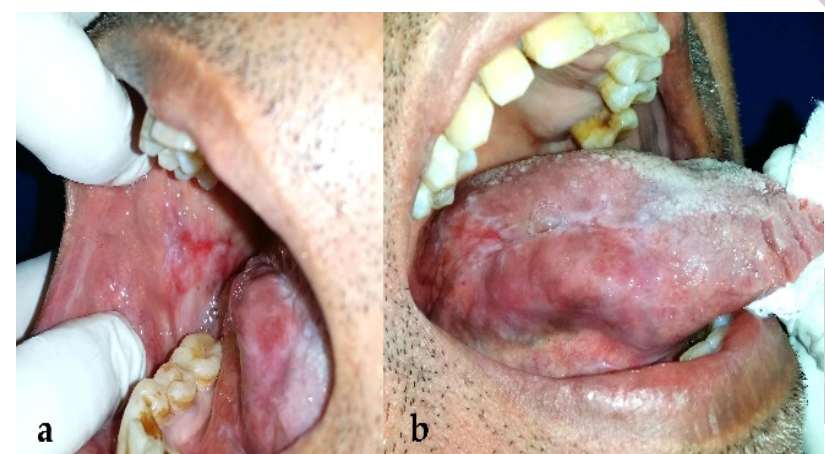

Figure 1: Clinical photographs of EOLP lesions. Lesions are present on the buccal mucosa and lateral borders of the tongue.

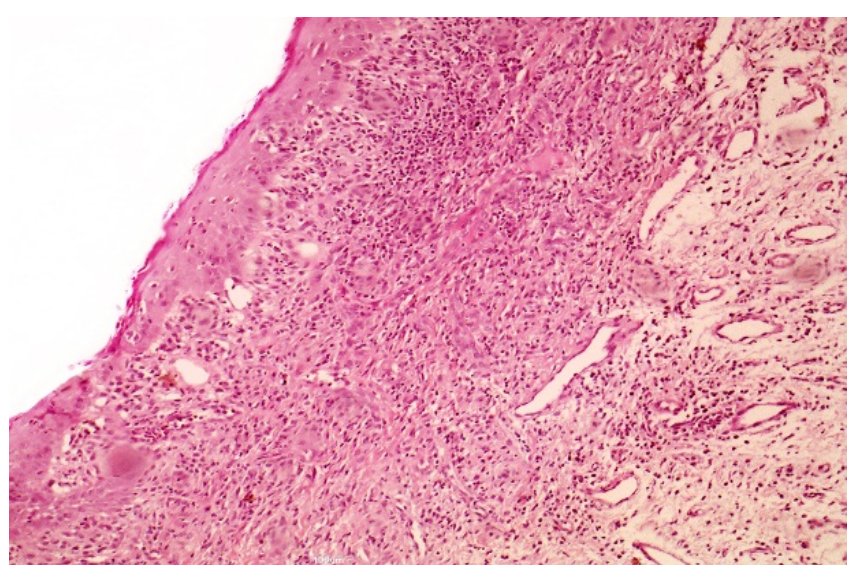

Figure 2: Photomicrograph of a case of EOLP. The section shows loss of surface epithelium, the underlying connective tissue shows high vascularity and a dense sub-epithelial lymphocytic band. H\&E x100

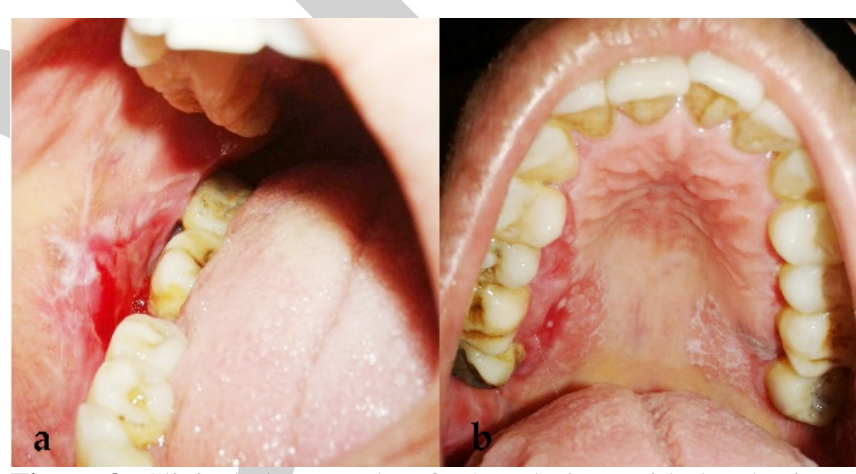

Figure 3: Clinical photographs of EOLP lesions with dysplastic changes. Lesions are present on the buccal mucosa and palate.

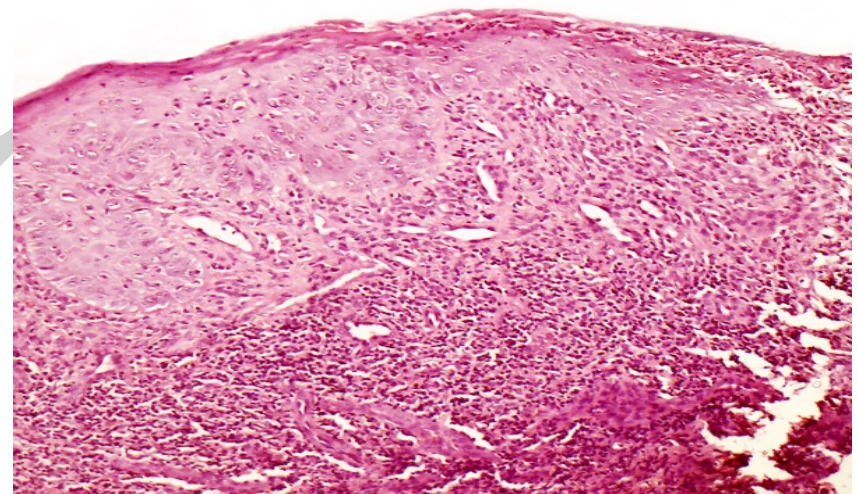

Figure 4: Photomicrograph of a case of EOLP. The section shows absence of surface epithelium, high connective tissue vascularity and a dense sub-epithelial lymphocytic band, dysplastic surface epithelium, drop shaped rete processes, hyperchromatism and pleomorphism. H\&E x200.

Saliva samples were obtained from all subjects and levels of TNF- $\alpha$ were estimated by enzyme-linked immunosorbent assay (ELISA) method (13).

\section{Biochemical analysis}

Unstimulated whole saliva was collected shortly after the diagnosis and before administration of definitive therapy 
under resting conditions, at least 1 hour after food intake. Subjects were asked to generate saliva in their mouth and spit into a wide test tube for 10 minutes (14).

Collected salivary samples were stored at $-80^{\circ} \mathrm{C}$. Stored saliva was melted and subjected to centrifugation for 20 minutes at the speed of 2000-3000 r.p.m. and the resultant supernatant was used for further biochemical analysis.

Levels of TNF-alpha were determined using AssayPro Human TNF- $\alpha$ ELISA Kit (AssayPro, USA) (13) (figure 5).

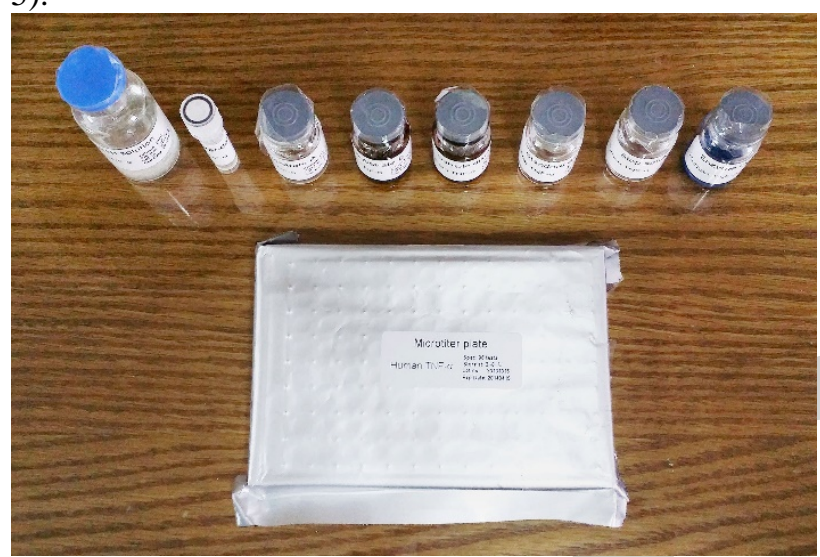

Figure 5: AssayPro Human TNF- $\alpha$ ELISA Kit (AssayPro, USA).

\section{Statistical analysis}

Data were fed to the computer and analyzed using IBM SPSS software package version 20.0 (15). Qualitative data were described using number and percent. Quantitative data were described using range (minimum and maximum), mean, standard deviation and median. Comparison between different groups regarding categorical variables was tested using Chi-square test. When more than $20 \%$ of the cells have expected count less than 5, correction for chi-square was conducted using Monte Carlo correction. For normally distributed data, comparison between more than two population were analyzed F-test (ANOVA) to be used. For abnormally distributed data, Kruskal Wallis test was used to compare between different groups, Significance of the obtained results was judged at the $5 \%$ level (16).

\section{RESULTS}

In this case control study, 14 patients were recruited and were divided into 2 equal groups. Group I consisted of patients suffering from EOLP and group II consisted of EOLP patients with dysplastic changes. Seven healthy subjects were also included in group III, the control group.

Table 1 presents the demographic data of the recruited subjects of all the studied groups regarding age and gender. The mean age was $48.86 \pm 8.61$ years in group I; $51.00 \pm 6.00$ years in group II and $47.86 \pm 10.37$ years in group III.

Table (1): Comparison between the different studied groups according to demographic data.

\begin{tabular}{|c|c|c|c|c|c|c|c|c|}
\hline & \multicolumn{2}{|c|}{$\begin{array}{l}\text { EOLP } \\
(n=7)\end{array}$} & \multicolumn{2}{|c|}{$\begin{array}{c}\text { EOLP/dys } \\
\text { p. } \\
(n=7)\end{array}$} & \multicolumn{2}{|c|}{$\begin{array}{l}\text { Control } \\
(n=7)\end{array}$} & \multirow[t]{2}{*}{$\begin{array}{c}\text { Test of } \\
\text { sig. }\end{array}$} & \multirow[t]{2}{*}{$\mathrm{p}$} \\
\hline & No. & $\%$ & No. & $\%$ & No. & $\%$ & & \\
\hline Gender & 2 & 28.57 & 3 & 42.86 & $\begin{array}{l}2 \\
5\end{array}$ & 28.57 & $\chi 2=2.01$ & $\mathrm{MCp}=$ \\
\hline Female & 5 & 71.43 & 4 & 57.14 & 5 & 71.43 & & 0.068 \\
\hline $\begin{array}{l}\text { Min. - } \\
\text { Max. }\end{array}$ & \multicolumn{2}{|c|}{$37-60$} & \multicolumn{2}{|c|}{$42-63$} & \multicolumn{2}{|c|}{$36-62$} & & \\
\hline Mean \pm SD & \multicolumn{2}{|c|}{$\begin{array}{c}48.86 \pm \\
8.61\end{array}$} & \multicolumn{2}{|c|}{$\begin{array}{c}51.00 \pm \\
6.00\end{array}$} & \multicolumn{2}{|c|}{$\begin{array}{c}47.86 \pm \\
10.37\end{array}$} & $F=3.11$ & 0.098 \\
\hline Median & \multicolumn{2}{|c|}{47.0} & \multicolumn{2}{|c|}{50.0} & \multicolumn{2}{|c|}{46.0} & & \\
\hline
\end{tabular}

$\chi 2$ : Vlaue for Chi square

MC: Monte Carlo test

$\mathrm{F}: \mathrm{F}$ test (ANOVA)

On comparing the three studied groups, it was found that patients in all groups were matched without any statistically significant difference regarding both age (P 0.098) and gender (P 0.068).

\section{Level of saliva TNF-o}

Table 2 and figure 6 show the comparison between the three groups regarding the level of TNF- $\alpha$. The mean value was $75.0 \pm 1.66 \mathrm{ng} / \mathrm{L}$ for group I; $82.17 \pm 1.79 \mathrm{ng} / \mathrm{L}$ for group II and $67.21 \pm 2.38 \mathrm{ng} / \mathrm{L}$ for group III.

Table (2): Statistical analysis of TNF-a (ng/L) in the different studied groups.

\begin{tabular}{|c|c|c|c|c|c|}
\hline & $\begin{array}{c}\text { EOLP } \\
(\mathrm{n}=7)\end{array}$ & $\begin{array}{c}\text { EOLP/dysp } \\
\cdot \\
(\mathrm{n}=7)\end{array}$ & $\begin{array}{c}\text { Control } \\
(\mathrm{n}=7)\end{array}$ & $\mathrm{F}$ & $\mathrm{p}$ \\
\hline TNF- $\alpha$ & & & & & \\
Min. - Max. & $72.5-77$ & $77.5-86.0$ & $63.5-69.5$ & 0.01 \\
Mean \pm SD. & $75.0 \pm 1.66$ & $82.17 \pm 1.79$ & $67.21 \pm 2.38$ & 9.29 & 1 \\
Median & 74.5 & 81.0 & 67.5 & & \\
\hline p1 & 0.042 & 0.010 & & \\
\hline p2 & 0.033 & & & \\
\hline
\end{tabular}

p1: p value for comparing between control and each other group p2: $p$ value for comparing between EOLP and EOLP/dysp. $\mathrm{F}: \mathrm{F}$ test (ANOVA) 


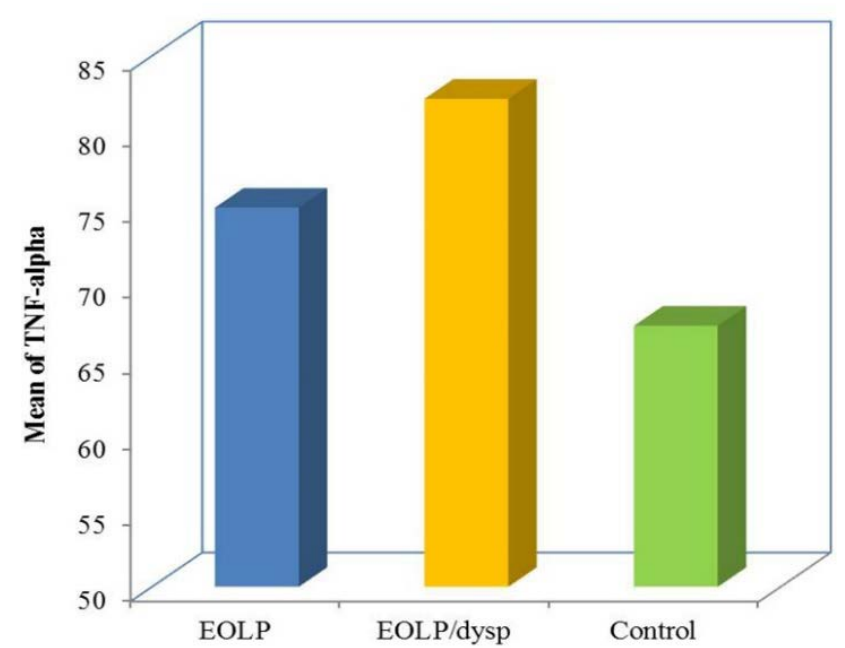

Figure 6: Comparison between the different studied groups according to TNF- $\alpha(\mathrm{ng} / \mathrm{L})$.

The level of TNF- $\alpha$ was higher in groups I and II when compared to the control group. This increase was statistically significant (p 0.042 and 0.010 , respectively). Moreover, a statistically significant difference was found when comparing the two study groups (I and II) together (P 0.033).

\section{DISCUSSION}

OLP is a persisting inflammatory keratotic disorder of oral mucosa with some characteristics of autoimmune disease (17). The WHO has grouped this lesion under the potentially malignant disorders (PMD) of the oral mucosa (18).

Despite that in OLP lesions mixed cytokines are simultaneously generated, TNF-alpha (TNF- $\alpha$ ) has been implicated to have a key role in the initiation and progression of the disease (12).

Saliva as a diagnostic fluid meets the demand for an inexpensive, non-invasive and collected repeatedly without discomfort to the patient (19). Unstimulated whole saliva (WUS) better represents the physiological state when compared to a stimulated state (20).

Our current study aimed to evaluate the salivary levels of TNF- $\alpha$ in EOLP. 21 patients were enrolled, they were divided into 3 groups diagnosed clinically and histologically as in the following manner with and without dysplastic changes. 14 are: group I constituting 7 EOLP patients, group II of 7 EOLP patients with dysplastic changes in addition to group III of 7 healthy subjects as control.

Results of our study revealed a statistically significant increase in the level of salivary TNF- $\alpha$ in EOLP patients when compared to healthy subjects.

In line with that, in 2010 Ghallab et al (21) demonstrated a statistically significant elevation in salivary levels of TNF- $\alpha$ in OLP samples compared to normal control.
Recently, Juretić et al (22) also reported that TNF- $\alpha$ was elevated in the saliva of patients with oral lichen planus in comparison to the controls which may have diagnostic and/or prognostic significance.

Regarding EOLP patients having dysplastic changes, a higher statistically significant increase in the level of salivary TNF- $\alpha$ was found when compared to the healthy controls.

In agreement to this, in 2005, Rhodus (23) analyzed and compared the level of TNF- $\alpha$ in WUS among OLP patients with dysplasia and individuals of control. In moderate and severe dysplasia, the level of TNF- $\alpha$ was significantly higher than in controls, being particularly elevated in the erosive form of the disease.

Our results also revealed that the levels of salivary TNF- $\alpha$ were significantly higher in EOLP patients, with and without dysplasia, being higher in group II patients exhibiting dysplastic changes.

In light of the above-mentioned data, we propose that the increase of salivary cytokines in patients with EOLP may be due to two aspects, local production from the cells of the inflammatory infiltration and/or by the keratinocytes themselves (24), and/or the loss of structural barriers in oral mucosa in the active inflammatory phase of EOLP (25).

However, our results suggest that salivary assay may be a more sensitive method to reflect the enhanced disease-related cytokine production in OLP patients. Zhang et al. (26) remarked that the salivary level of TNF$\alpha$, was much higher than their serum partners. This stresses on the diagnostic and prognostic potential of salivary TNF- $\alpha$ in OLP patients and may lead to more specific and more effective therapies.

\section{CONCLUSIONS}

TNF- $\alpha$ plays a role in pathogenesis and carcinogenesis of EOLP.

Salivary TNF- $\alpha$ can be used as a useful marker and indicator for subjects at high risk to develop OLP as a potentially malignant lesion.

Salivary markers can be used as a non-invasive method of diagnosis.

\section{CONFLICT OF INTEREST}

The authors declare that they have no conflicts of interest.

\section{REFERENCES}

1. Scrobota I, Mocan T, Catoi C, Bolfa P, Muresan A, Baciut G. Histopathological aspects and local implications of oxidative stress in patients with oral lichen planus. Rom J Morphol Embryol 2011; 52: 1305-9.

2. Bajaj DR, Khoso NA, Devrajani BR, Matlani BL, Lohana P. Oral lichen planus: a clinical study. J Coll Physicians Surg Pak 2010; 20: 154-7.

3. Daoud MS, Pittelkow MR. Lichen planus. In: Wolff K, Goldsmith LA, Katz SI, Gilchrest BA, Paller AS, Leffell 
DJ (eds). Fitzpatrick's dermatology in general medicine. $7^{\text {th }}$ ed. New York: McGraw-Hill, 2008. pp 244-12.

4. Warnakulasuriya S, Johnson NW, van der Waal I. Nomenclature and classification of potentially malignant disorders of the oral mucosa. J Oral Pathol Med 2007; 36: 575-80.

5. Srinivas K, Aravinda K, Ratnakar P, Nigam N, Gupta S. Oral lichen planus - Review on etiopathogenesis. Natl J Maxillofac Surg 2011; 2: 15-6.

6. Thornhill MH. Immune mechanisms in oral lichen planus. Acta Odontol Scand 2001; 59: 174-7

7. Simark-Mattsson C, Bergenholtz G, Jontell M. Distribution of interleukin-2, -4, -10, tumor necrosis factor-alpha and transforming growth factor-b mRNAs in oral lichen planus. Arch Oral Biol 1999; 44: 499-507.

8. Abram M, Vuckovic D, Wraber B, Doric M. Plasma cytokine response in mice with bacterial infection. Mediat Inflamm 2000; 9: 229-34.

9. Nakao S, Kuwano T, Ishibashi T, Kuwano M, Ono M. Synergistic effect of TNF-alpha in soluble VCAM-1induced angiogenesis through alpha 4 integrins. J Immunol 2003; 170: 5704-11.

10. Scott KA, Moore RJ, Arnott CH. An anti-tumor necrosis factor-alpha antibody inhibits the development of experimental skin tumors. Mol Cancer Ther 2003; 2: 44551.

11. Sugermann PB, Savage NW, Seymour GJ, Wals LJ. Is there a role for tumor necrosis factor-alpha (TNFalpha) in oral lichen planus? J Oral Pathol Med 1996; 25: 219-24.

12. Yammamoto T, Yoneda K, Ueta E, Osaki T. Serum cytokines, interleukin-2 receptor, and soluble intercellular adhesion molecule-1 in oral disorders. Oral Surg Oral Med Oral Pathol 1994; 78: 727-35.

13. Navazesh M. Methods for collecting saliva. Ann N Y Acad Sci 1993; 694: 72-7.

14. Taylor PC. Anti-TNF therapy for rheumatoid arthritis and other inflammatory diseases. Mol Biotechnol 2001; 19: 153-68.

15. Kirkpatrick LA, Feeney BC. A simple guide to IBM SPSS statistics for version 20.0. Student ed. Belmont, Calif.: Wadsworth, Cengage Learning, 2013. p. 115.

16. Daly LE, Bourke GJ, McGilvray J. Statistical analysis. In: Interpretation and uses of medical statistics. 4th ed. Oxford: Scientific Publications(pub), 1991. p. 411-6.

17. Mollaoglu N. Oral lichen planus: a review. Br J Oral Maxillofac Surg 2000; 38: 370-7.

18. Sarode SC, Sarode GS, Karmarkar S, Tupkari JV. A new classification for potentially malignant disorders of the oral cavity. Oral Oncol 2011; 47: 920-1.

19. Nagler R, Bahar G, Shpitzer T, Feinmesser R. Concomitant analysis of salivary tumor markers-a new diagnostic tool for oral cancer. Clin Cancer Res 2006; 12: 3979-84.

20. Nishanian R, Aziz N, Chung J, Detels R, Fahey JL. Oral fluids as an alternative to serum for measurement of markers on immune activation. Clin Diagn Lab Immunol 1998; 5: 507-12.
21. Ghallab NA, el-Wakeel N, Shaker OG. Levels of salivary IFN-gamma, TNF-alpha, and TNF receptor-2 as prognostic markers in (erosive) oral lichen planus. Mediators Inflamm 2010; 2010: 847632.

22. Juretić M, Cerović R, Belušić-Gobić M, Brekalo Pršo I, Kqiku L. Salivary levels of TNF-alpha \pm and IL-6 in patients with oral premalignant and malignant lesions. Folia Biol (Praha) 2013; 59: 99-102.

23. Rhodus NL, Cheng B, Myers S, Miller L, Ho V, Ondrey F. The feasibility of monitoring NF-kappaB associated cytokines: TNF-alpha, IL-1alpha, IL-6, and IL-8 in whole saliva for the malignant transformation of oral lichen planus. Mol Carcinog 2005; 44: 77-82.

24. Saliou C, Kitazawa M, McLaughlin L, Yang JP, Lodge JK, Tetsuka T, et al. Antioxidants modulate acute solar ultraviolet radiationinduced NF-kappa-B activation in a human keratinocyte cell line. Free Radic Biol Med 1999; 26: $174-83$.

25. Dale BA. Fascination with epithelia. Architecture, proteins, and functions. J Dent Res 2003; 82: 866-9.

26. Zhang Y, Lin M, Zhang S, Wang Z, Jiang L, Shen J, et al. NF-kappaB-dependent cytokines in saliva and serum from patients with oral lichen planus: a study in an ethnic Chinese population. Cytokine 2008; 41: 1449 . 